\title{
Opportunities for recovery at work and excellent work ability - a cross-sectional population study among young workers
}

\author{
Maria Boström ${ }^{1 *}$, Judith K. Sluiter ${ }^{2}$, Mats Hagberg ${ }^{1}$ and Anna Grimby-Ekman ${ }^{1,3}$
}

\begin{abstract}
Background: Better opportunities for recovery at work are thought to be associated with work ability in a young workforce but evidence is scarce to lacking. The aim of this study was to examine cross-sectional associations between opportunities for recovery at work and excellent work ability among young workers and specifically for young workers with high work demands.

Methods: A study group of 1295 women and 1056 men aged 18-29 years was selected from three biennial years of a population cohort. The subsample reporting high work demands consisted of 439 women and 349 men. The study group had completed a work environment questionnaire in a survey conducted by Statistics Sweden. Associations between opportunities for recovery at work and excellent work ability were assessed by multiple logistic regression models stratified for gender.

Results: Having varied work was associated with excellent work ability in all young men $(p<0.0006$; prevalence ratio [PR] 1.3) and also specifically in men with high work demands ( $p=0.019 ; \mathrm{PR} 1.3)$. For the latter group the possibility of deciding when to perform a work task was also associated with excellent work ability ( $p=0.049$; PR 1.3). Among young women with high work demands, the possibility of deciding one's working hours was associated with excellent work ability ( $p=0.046$; PR 1.2).

Conclusions: For young men, having varied work can contribute to excellent work ability. In addition, for men with high work demands, the possibility of deciding when to perform a work task may be favourable for excellent work ability. For young women with high work demands, the possibility of deciding one's working hours can contribute to excellent work ability. Employers could use these opportunities for recovery in promoting work ability among young workers.
\end{abstract}

Keywords: Varied work, Work ability score, Young workforce, Worktime control, Work-health promotion

\section{Background}

Young adults need good work ability to sustain them through a long working life as they replace the aging population [1]. Opportunities for recovery at work may be very important to this group as work environments for young workers, especially young women, are reported to be declining [2]. To our knowledge, however, associations between recovery opportunities at work and work ability have not previously been studied among young workers.

\footnotetext{
* Correspondence: maria.bostrom@amm.gu.se

${ }^{1}$ Department of Occupational \& Environmental Medicine, Sahlgrenska

University Hospital, Postal: Box 414SE 40530 Gothenburg, Sweden

Full list of author information is available at the end of the article
}

The definition of work ability can vary in different fields. In occupational health it is commonly defined as the balance between individual resources (e.g., health, knowledge, and attitudes) and working conditions (e.g., content, demands, and organization) [1]. In the present study work ability was measured by the work ability score (WAS) assessed in the work ability index (WAI) [3].

Several definitions for the concept of recovery include situational characteristics that diminish load effects [4], a need to recuperate from work-induced fatigue experienced primarily after a day of work [5], and a desire to be temporary relieved from demands in order to restore one's resources [6]. As the last two definitions are related 
more to personal needs for immediate recovery, than to recovery opportunities afforded by structural aspects of work, the first definition was used in the current study.

Flexible working conditions have been found to offer recovery opportunities associated with health and well-being [7]. Worktime control has also been shown to be a promising tool to maintain health, well-being, and job-related outcomes, including performance [8]. The possibility of taking breaks at work and influencing other aspects of one's working hours has been shown to have positive effects on work-related fatigue, sleep, and health complaints, but not on future absenteeism [4]. Rest breaks were shown in one review to have a positive effect on performance and productivity [9], while another review found that flexible and compressed workweek schedules also offered recovery opportunities that had a positive effect on performance and productivity [10]. Although several recovery opportunities at work have been studied and seem to have an effect on health, well-being, performance, and productivity, these have not been studied specifically in young workers.

Though no studies of associations between recovery opportunities at work and work ability have been found for young workers, there are some closely related studies. In an interview study on work ability, recovery opportunities at work were included in a nuanced picture of experiences of work ability among young workers [11]. Further, young women have been found to strive for balance between stress and recovery at work to maintain their health and work ability [12]. One interesting hypothesis suggests that lack of recovery associated with prolonged work schedules and overtime can generate pressure on work ability among young workers [13], but specific recovery opportunities at work are not discussed.

Because young workers (aged 16-29 years), especially young women, report more strenuous work and experience more fatigue after work than older workers [2], recovery opportunities during the working day could be important in promoting excellent work ability. According to this report by the Swedish Work Environment Authority, young workers had less opportunity to decide when to do a work task and had more monotonous work than older workers; consequently, the work environment of young Swedish workers is poorer and includes fewer recovery opportunities that that of workers aged 30 years and older. Young workers with high work demands most likely have a greater need of recovery at work and hence a work environment with recovery opportunities than those with fewer demands [14].

The concept of recovery is complex. It includes both recovery during the work day (internal) and recovery between work days (external) [14]. While we recognize this complexity, the present study focused solely on recovery opportunities at work since this topic appears to be unexplored among young workers.
The aim of this study was to investigate the association between opportunities for recovery at work and excellent work ability among young workers, especially for young workers with high work demands. Specific research questions were: i) is the probability higher to report excellent work ability when a higher degree of recovery opportunities at work are present?, ii) does the association in i) for the total sample hold when adjusted for high work demands and educational level? and iii) is the association between recovery opportunities at work and excellent work ability stronger among those with high work demands?

\section{Methods}

\section{Study design and data collection}

This is a cross-sectional population study using the Work Environment Survey by Statistics Sweden on behalf of the Swedish Work Environment Authority. This survey is based on the Labour Force Survey and includes additional questions asked in a telephone interview and a follow-up postal questionnaire. The purpose of the survey is to describe the physical and psychosocial work environment of the employed population. The employed population was defined as those aged 16-64 years who worked at least one hour during the measurement week. The Work Environment Survey has been conducted every second year since 1989. For each of the years 2009, 2011, and 2013 the randomized selected sample was about $10000-16000$, of whom approximately 8100- 12400 answered the telephone interview and about 4800-7800 also answered the postal questionnaire. The telephone interview asks participants background questions on employment, work strain, leadership, and work ability. A week later the postal questionnaire asks about 121 specific occupational and health items. The development and validation of the method is described in a report from Statistics Sweden [15].

\section{Study sample}

In 2009-2013 about 19000 individuals responded to the full telephone interview. Of these 4949 were young workers, 18-29 years of age. The study sample consists of 2351 young workers who responded to the telephone interview, the postal questionnaire, and the WAS question in the telephone interview (Fig. 1). There was no overlap of individuals in the three years chosen for the study. Inclusion criteria for the study sample were age range 18-29 years, and having answered the single WAS question. For the subsample of individuals with high work demands, $N=788$, the criterion was to have reported having either a job that was generally physically strenuous to a large extent or a high workload with far too much to do to a large extent, or both. The selection of this subsample was chosen as women and men with high work demands could have an increased need of recovery opportunities at work [14]. 


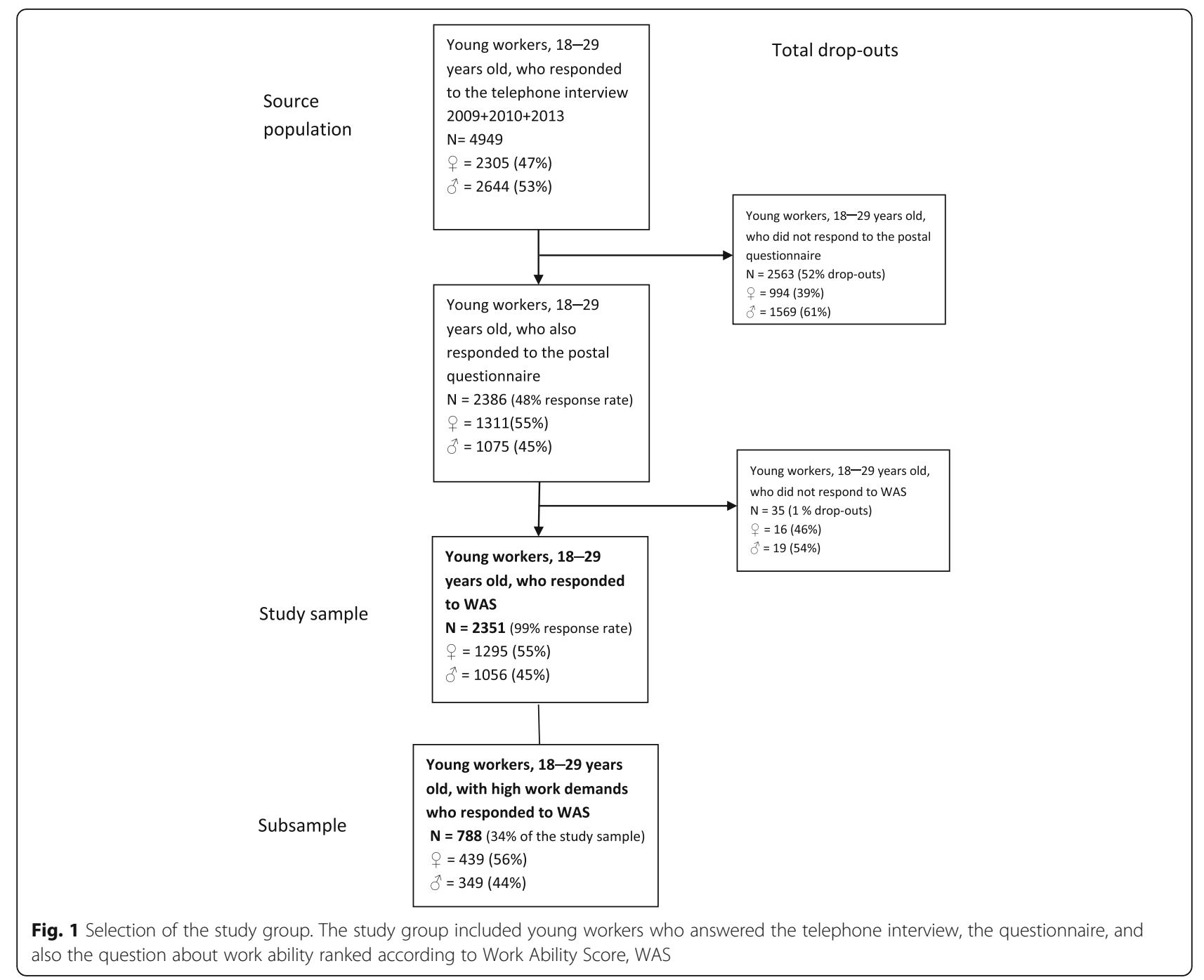

\section{Individual characteristics}

Individual characteristics drawn from the survey were used to describe the sample: sex, age, education, years in present occupation, trade, work ability, and health. The variable educational level was dichotomized into compulsory school or high school versus post-gymnasium, college, or university. Three health variables were identified: pain in at least one location including upper back or neck, lower back, shoulder or arms, wrists or hands, and hips, legs, knees or feet; feeling very tired after work; and sleep difficulties due to thoughts of work. These health variables were ranked by frequency: every day, a few days per week, a day per week, a few days per month, seldom or not at all. The three first alternatives implied impaired health.

\section{Outcome}

\section{Excellent work ability}

Work ability can be measured by using part of the work ability index (WAI), a Finnish self-report instrument with seven dimensions measured on 10 items, by which individuals assess their own work ability [1]. In the present survey work ability was measured by using the WAS [3], taken from, and shown to correspond with, the WAI $[16,17]$. The WAS measures "current work ability compared with the lifetime best" on a scale ranging from 0 "cannot work at all right now" to 10 "my work ability is at its best right now". Excellent work ability was ranked 10 on the scale, as in other studies $[3,16]$.

\section{Explanatory variables}

\section{Recovery opportunities at work}

Because of the lack of knowledge of possible associations between recovery opportunities at work and excellent work ability, the five items measuring recovery opportunities at work in this study were chosen mainly from research about associations between recovery opportunities at work and health, well-being, performance, and productivity. Factors in accord with the Recovery Opportunity Scale [4], which 
measures recovery opportunities in relation to health, were also used. Overall, the items in the questionnaire were used to assess opportunities for recovery at work, not lack of recovery at work.

The first question, on the possibility of deciding one's own working hours $[4,10,18]$, had three answer alternatives: "Yes, I can be on flexitime", "Yes, I have in other ways relatively free working hours", and "No, I cannot influence my working hours". The first two alternatives were considered recovery opportunities.

The second question asked about the possibility of deciding the work pace. Although this was not previously considered a recovery factor [19], it was included in the hypothesis because it occurs in regulations on workers' opportunities to influence their own work [20]. A third question asked about the possibility of taking short breaks at any time to talk, $[4,9,18]$. These two questions had the same response alternatives:" nearly all the time" and "about three quarters of the time" represented recovery opportunities at work, in contrast to the alternatives of "half the time", "about a quarter of the time", "a little" and "no, not at all".

The fourth question, about the possibility of deciding when to perform a work task [8], was answered by "always", "mostly", "mostly not", or "never", with the two first alternatives signifying recovery opportunities at work. The fifth and last question asked about variation in the respondents' work. On a scale of $0-5$, responses ran from "monotonous work" to "varied work", and ratings of 4 and 5 indicated an opportunity for recovery at work. This question was chosen because the opportunity to take spontaneous breaks increases with varied work [14].

\section{Possible confounders}

High work demand was seen as a possible confounder for the analyses of the total sample to answer the first research question. This variable was, however, also used for creating a subsample, as described in the study sample section, to answer the third research question. For the second research question, two possible confounders were considered: high work demands and educational level. High work demands can influence work ability [21] and have a negative association with recovery opportunities at work [14] and was defined in terms of physically strenuous work to a large extent and/or high workload with far too much to do to a large extent. Poor basic education has been shown to relate to poor work ability among young adults [13] and was therefore considered as a confounder.

\section{Statistical analysis}

SAS version 7.11 (SAS Institute, Cary, NC, USA) was used for the analyses in this study. In all analyses the data were stratified for women and men [22]. A subsample of those with high work demands was also analyzed. Descriptive data were obtained through frequency analyses.

The associations between recovery opportunities at work and excellent work ability was analyzed with logistic regressions (proc genmod in SAS). The effect measures retrieved from these regressions were prevalence ratios (PRs) instead of the commonly used odd ratios (ORs). This is due to the outcome being common and hence ORs cannot be interpreted as approximations of PRs. From the logistic regressions PRs were calculated as the effect of the exposure around the prevalence of $50 \%$. In the presented PRs the group with the lower degree of recovery opportunities at work was used as the reference category. The $95 \%$ confidence intervals (CIs) for PRs were calculated using the delta method [23].

A guideline of applied logistic regression was followed [24] to build models for testing associations between recovery opportunities at work and excellent work ability. Co-linearity was checked by examining pairwise correlations by cross tables considering $>80 \%$ in a diagonal or any cells with no answers. This was performed between all exposure variables, between all exposure variables and the possible confounders of high work demands and educational level, and between the two confounders. "Being involved in planning the work" showed co-linearity with the variable "Possibility of deciding when to perform a work task". "Being involved in planning the work" was therefore excluded from further analyses due to more missing compared to "Possibility of deciding when to perform a work task". Univariate logistic regression analyses were then performed to select variables for the multiple regression with the criteria of $p<0.25$.

The steps in the guideline for creating multiple models set criteria for variable inclusion at $p<0.25$, changes in parameter estimates for exposure variables at $<15 \%$, and likelihood ratio tests between nested models. If an explanatory variable had $p \geq 0.25$, but changed parameter estimates for other explanatory variables when the models were considered with and without it, it was included as a confounder. Possible interactions between exposure factors were also tested.

\section{Ethics}

This study was approved by the Regional Ethical Review Board at the University of Gothenburg, Sweden (Reg.no. 221-15).

\section{Results}

\section{Characteristics of the study sample}

The proportion of women was $55 \%$ in the study sample and $56 \%$ in the subsample (Table 1). High work demands were reported by $34 \%$ of the women $(N=439)$ and $33 \%$ of the men $(N=349)$. Self-reported work ability was high for women and men (9.2) overall and in the 
Table 1 Characteristics of the study sample and the subsample

\begin{tabular}{|c|c|c|c|c|c|c|c|c|}
\hline \multirow{2}{*}{$\begin{array}{l}\text { Young workers without/with high work demands } \\
N=2351 / N=788\end{array}$} & \multicolumn{2}{|l|}{ Women } & \multicolumn{2}{|c|}{$\begin{array}{l}\text { Women with high } \\
\text { work demands }\end{array}$} & \multicolumn{2}{|l|}{ Men } & \multicolumn{2}{|l|}{$\begin{array}{l}\text { Men with high } \\
\text { work demands }\end{array}$} \\
\hline & \multicolumn{2}{|l|}{$N=1295(55 \%)$} & \multicolumn{2}{|l|}{$N=439(56 \%)$} & \multicolumn{2}{|l|}{$N=1056(45 \%)$} & \multicolumn{2}{|l|}{$\mathrm{N}=349(44 \%)$} \\
\hline \multicolumn{9}{|l|}{ Individual factors } \\
\hline Work ability: mean & 9.2 & & 9.0 & & 9.2 & & 9.1 & \\
\hline range & $1-10$ & & $1-10$ & & $1-10$ & & $1-10$ & \\
\hline SD & 1.3 & & 1.4 & & 1.2 & & 1.4 & \\
\hline Age in years: mean & 24.3 & & 24.3 & & 24.8 & & 24.7 & \\
\hline range & $18-29$ & & $18-29$ & & $18-29$ & & $18-29$ & \\
\hline SD & 3.3 & & 3.2 & & 3.2 & & 3.1 & \\
\hline Years in present occupation: mean & 2.5 & & 2.8 & & 3.1 & & 3.7 & \\
\hline range & $1 / 12-14$ & & $1 / 12-14$ & & $1 / 12-15$ & & $1 / 12-15$ & \\
\hline \multirow[t]{2}{*}{ SD } & 2.3 & & 2.5 & & 2.5 & & 2.8 & \\
\hline & $\mathrm{N}$ & $\%$ & $\mathrm{~N}$ & $\%$ & $\mathrm{~N}$ & $\%$ & $\mathrm{~N}$ & $\%$ \\
\hline Excellent work ability & 814 & 63 & 252 & 57 & 673 & 64 & 204 & 58 \\
\hline \multicolumn{9}{|l|}{ Educational level } \\
\hline Compulsory school/high school & 705 & 55 & 261 & 60 & 692 & 66 & 261 & 75 \\
\hline Post-gymnasium/college/university & 574 & 45 & 173 & 40 & 356 & 34 & 85 & 25 \\
\hline $\begin{array}{l}\text { Pain in at least one location of the body at least one } \\
\text { day per week the last three months }\end{array}$ & 791 & 62 & 318 & 75 & 452 & 44 & 198 & 58 \\
\hline $\begin{array}{l}\text { Tired out after work at least one day per week the } \\
\text { last three months }\end{array}$ & 699 & 55 & 324 & 75 & 515 & 49 & 245 & 71 \\
\hline $\begin{array}{l}\text { Sleep difficulties due to thoughts of the work keeping you } \\
\text { awake at least one day per week the last three months }\end{array}$ & 246 & 19 & 113 & 26 & 155 & 15 & 70 & 20 \\
\hline \multicolumn{9}{|l|}{ Recovery opportunities } \\
\hline \multicolumn{9}{|l|}{ Possibility of deciding working hours } \\
\hline Yes, flexible working hours or free working hours & 742 & 58 & 208 & 48 & 616 & 59 & 164 & 47 \\
\hline No, cannot influence working hours & 544 & 42 & 229 & 52 & 433 & 41 & 184 & 53 \\
\hline \multicolumn{9}{|l|}{ Possibility of deciding the work pace } \\
\hline At least $3 / 4$ of the time & 484 & 38 & 114 & 26 & 495 & 47 & 145 & 42 \\
\hline At most half of the time & 803 & 62 & 322 & 74 & 557 & 53 & 204 & 58 \\
\hline \multicolumn{9}{|l|}{ Possibility of taking short breaks } \\
\hline At least $3 / 4$ of the time & 495 & 39 & 106 & 24 & 577 & 55 & 155 & 45 \\
\hline At most half of the time & 790 & 61 & 330 & 76 & 466 & 45 & 189 & 55 \\
\hline \multicolumn{9}{|l|}{ Possibility of deciding when to perform a work task } \\
\hline Mostly or always & 581 & 45 & 152 & 35 & 604 & 58 & 172 & 50 \\
\hline Mostly not or never & 701 & 55 & 280 & 65 & 445 & 42 & 174 & 50 \\
\hline \multicolumn{9}{|l|}{ Having work that is mostly } \\
\hline Varied & 548 & 43 & 172 & 40 & 411 & 39 & 126 & 36 \\
\hline Monotonous & 740 & 57 & 263 & 60 & 635 & 61 & 222 & 64 \\
\hline
\end{tabular}

( $N$ number of workers, $S D$ standard deviation)

group with high work demands (9.0-9.1). The young workers, especially women, generally had few years of work experience. The men seemed to have lower educational levels than the women, especially among those with high work demands.
The young women and men tended to work in different trades (not shown in the tables). The largest group of women, both in the whole sample and in the subsample with high work demands, was found in the service, health care, and retail sector. Men were most often 
employed in construction and manufacturing, and then in the service, health care, and retail sector, though men with high work demands worked mainly in construction and manufacturing.

Women with high work demands reported the poorest health (pain, fatigue, and sleep difficulties), although pain and fatigue were common in the whole sample (Table 1).

Recovery opportunities at work were reported at various levels, as about half of the study sample experienced some recovery at work. Those with high work demands, especially women, seemed to report fewer of several of the investigated recovery variables than the sample as whole. Possibilities of deciding one's own working hours and to have varied work appeared to be quite similar for women and men in general, but at least the first variable seemed to be less common among those with high work demands.

\section{Associations between recovery opportunities at work and excellent work ability}

Univariate associations between recovery opportunities at work and excellent work ability for both young women and men are presented in Table 2. For men only, possibility of deciding the work pace, possibility of taking short breaks, possibility of deciding when to perform a work task, and varied work showed unadjusted associations with excellent work ability. For men with high work demands, all of these variables except for possibility of taking short breaks also showed unadjusted associations with excellent work ability.

The variables included in the multiple models are shown in Table 3. For women, the exposure variable possibility of deciding working hours was included in the multiple model I with $p=0.08$. In the multiple model II the same exposure variable was included; however, $p$ fell to 0.1. Possibility of deciding the work pace was included in both these models only to adjust the models and thus should be viewed as a confounder. In the multiple model III for women with high work demands, both possibility of deciding working hours and possibility of deciding the work pace were included, however, with $p=0.1$ and $p=0.2$, respectively. In the multiple model IV for women only possibility of deciding working hours was included with $p=0.046$.

Model I for the study sample of women included neither of the specified confounders (high work demands and educational level), but model II for the study sample of women included high work demands, Table 3. Further, model III for the subsample of women did not include the educational confounder, but model IV for the subsample of women did.

Other exposure variables were included in the multiple models for men. Having reported varied work was included in the two multiple models for all men, I and II, and also for men with high work demands, models III and IV, all with $p<0.05$. Possibility of deciding when to perform a work task was included in both models I and

Table 2 Univariate associations between recovery opportunities at work and excellent work ability

\begin{tabular}{|c|c|c|c|c|c|c|c|c|}
\hline \multirow[b]{4}{*}{ Recovery opportunities at work } & \multicolumn{4}{|l|}{ Women } & \multicolumn{4}{|c|}{ Women with high work demands } \\
\hline & \multirow{3}{*}{ Exposed (n) } & \multirow{3}{*}{ Cases (n) } & \multicolumn{2}{|c|}{$N=1282-1289$} & \multirow{3}{*}{ Exposed (n) } & \multirow{3}{*}{ Cases (n) } & \multirow{2}{*}{\multicolumn{2}{|c|}{$\begin{array}{l}\mathrm{N}=435-437 \\
\text { Univariate model }\end{array}$}} \\
\hline & & & \multicolumn{2}{|c|}{ Univariate model } & & & & \\
\hline & & & PR & $(95 \% \mathrm{Cl})$ & & & PR & $(95 \% \mathrm{Cl})$ \\
\hline Possibility of deciding working hours & 742 & 485 & 1.1 & $(0.998-1.26)$ & 208 & 130 & 1.2 & $(0.98-1.44)$ \\
\hline Possibility of deciding the work pace & 484 & 316 & 1.1 & $(0.96-1.22)$ & 114 & 73 & 1.2 & $(0.94-1.48)$ \\
\hline Possibility of taking short breaks & 495 & 322 & 1.1 & $(0.95-1.20)$ & 106 & 63 & 1.1 & $(0.82-1.29)$ \\
\hline Possibility of deciding when to perform a work task & 581 & 374 & 1.1 & $(0.94-1.18)$ & 152 & 92 & 1.1 & $(0.88-1.33)$ \\
\hline \multirow[t]{4}{*}{ Having mostly varied work } & 548 & 356 & 1.1 & $(0.95-1.20)$ & 172 & 101 & 1.0 & $(0.83-1.24)$ \\
\hline & \multirow{2}{*}{\multicolumn{2}{|c|}{ Men }} & & & \multicolumn{4}{|c|}{ Men with high work demands } \\
\hline & & & \multicolumn{2}{|c|}{$N=1043-1053$} & & & \multicolumn{2}{|c|}{$N=344-349$} \\
\hline & Exposed (n) & Cases (n) & \multicolumn{2}{|c|}{ Univariate model } & Exposed (n) & Cases (n) & \multicolumn{2}{|c|}{ Univariate model } \\
\hline Recovery opportunities at work & & & $P R$ & $(95 \% \mathrm{Cl})$ & & & $P R$ & $(95 \% \mathrm{Cl})$ \\
\hline Possibility of deciding working hours & 616 & 401 & 1.1 & $(0.93-1.21)$ & 164 & 98 & 1.0 & $(0.82-1.27)$ \\
\hline Possibility of deciding the work pace & 495 & 343 & 1.2 & $(1.09-1.41)$ & 145 & 96 & 1.3 & $(1.03-1.62)$ \\
\hline Possibility of taking short breaks & 577 & 394 & 1.2 & $(1.09-1.41)$ & 155 & 99 & 1.3 & $(0.98-1.53)$ \\
\hline Possibility of deciding when to perform a work task & 604 & 414 & 1.3 & $(1.11-1.43)$ & 172 & 114 & 1.4 & $(1.06-1.66)$ \\
\hline Having mostly varied work & 411 & 296 & 1.4 & $(1.17-1.54)$ & 126 & 86 & 1.4 & $(1.06-1.71)$ \\
\hline
\end{tabular}

$(N$ number of workers included in the univariate analyses, $n$ number of workers exposed for the variable respectively being a case, $P R$ prevalence ratios, $95 \% \mathrm{Cl}=95 \%$ confidence interval) 
Table 3 Multiple regression model. Parameter estimates (b coefficient) and $p$ ( $p$-values) for associations between recovery opportunities at work and excellent work ability for the study sample and the subsample

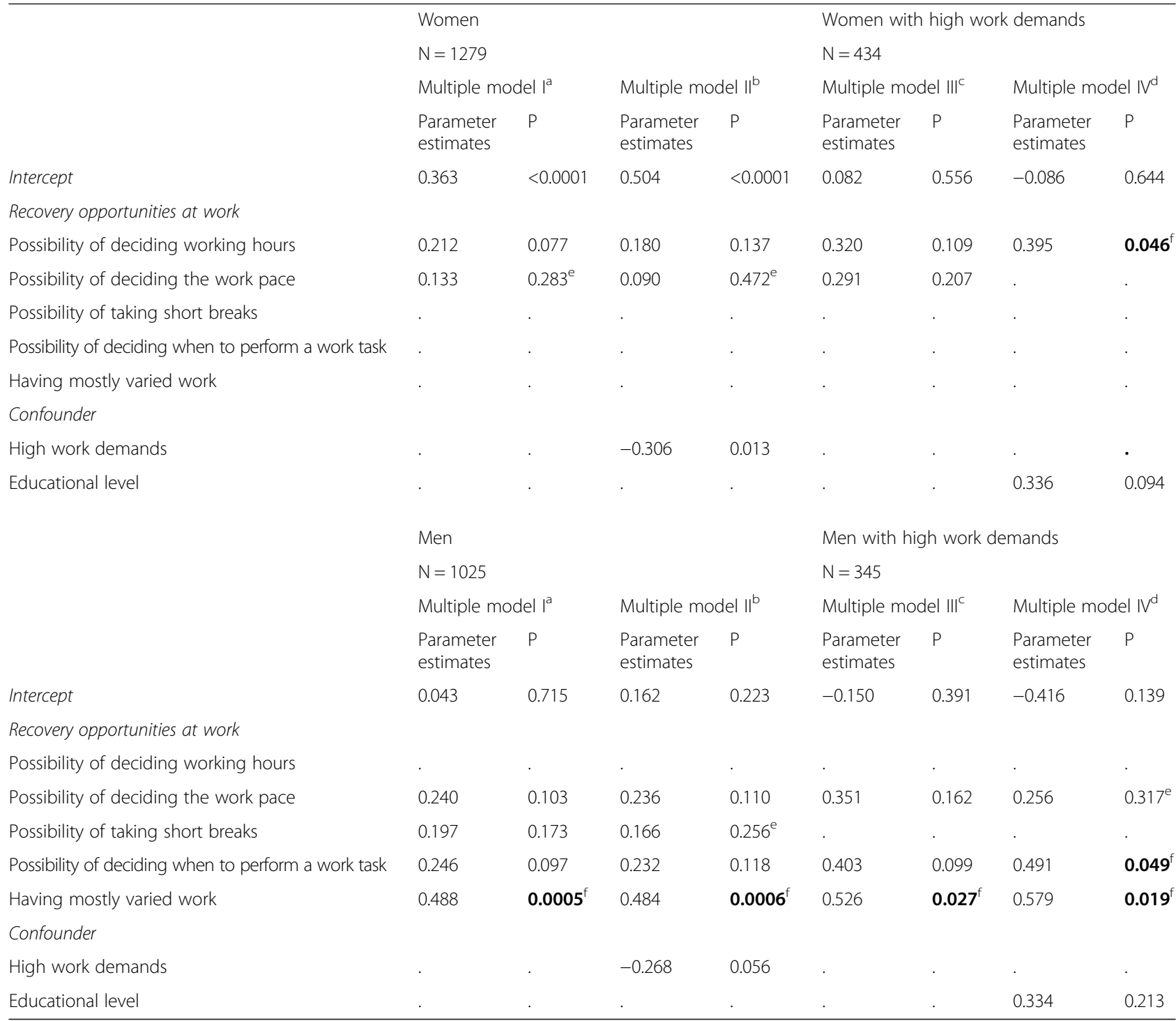

${ }^{a}$ Multiple model with no confounders. ${ }^{b}$ Multiple model with two confounders: high work demands and educational level. ${ }^{\mathrm{c} M u l t i p l e}$ model for the subsample with no confounders. ${ }^{\mathrm{d}}$ Multiple model for the subsample with one confounder: educational level. ${ }^{e}$ Variable included only to adjust the multiple model. ${ }^{f}$ The bold figures representing $p$-values $<0.05$. ( $\mathrm{N}=$ number of workers included in the multiple analyses,.$=$ the variable was not included in the multiple model)

III, with $p=0.097$ and $p=0.099$, respectively. In model II, this exposure variable was included with $p=0.1$, and in model IV, $p$ for this variable was 0.049 . Possibility of deciding the work pace was included in models I, II, and III, with $p=0.1, p=0.1$, and $p=0.2$, respectively. Finally, the variable possibility of taking short breaks was included, with $p=0.2$ for all men in model I. In model II this exposure variable was only included to adjust the multiple model, as was possibility of deciding the work pace in model IV, and these should therefore be seen as confounders.

Similar to women, shown in Table 3, model I for the study sample of men included neither of the specified confounders (high work demands and educational level), and model II for the study sample of men included high work demands. Further, model III for the subsample of men did not include the educational confounder, but model IV for the subsample of men did, also in similarity with women.

The size of the effect of recovery opportunities at work on excellent work ability for young women is shown in Table 4 and for young men in Table 5. The largest effects were found for men who reported varied work ( $\mathrm{PR}=1.3$ in all models), for men with high work demands with possibility of deciding when to perform a work task $(\mathrm{PR}=1.3$, model IV), and for women with high work 
Table 4 Prevalence ratios. Prevalence ratios based on multiple regression models for associations between recovery opportunities at work and excellent work ability for young women

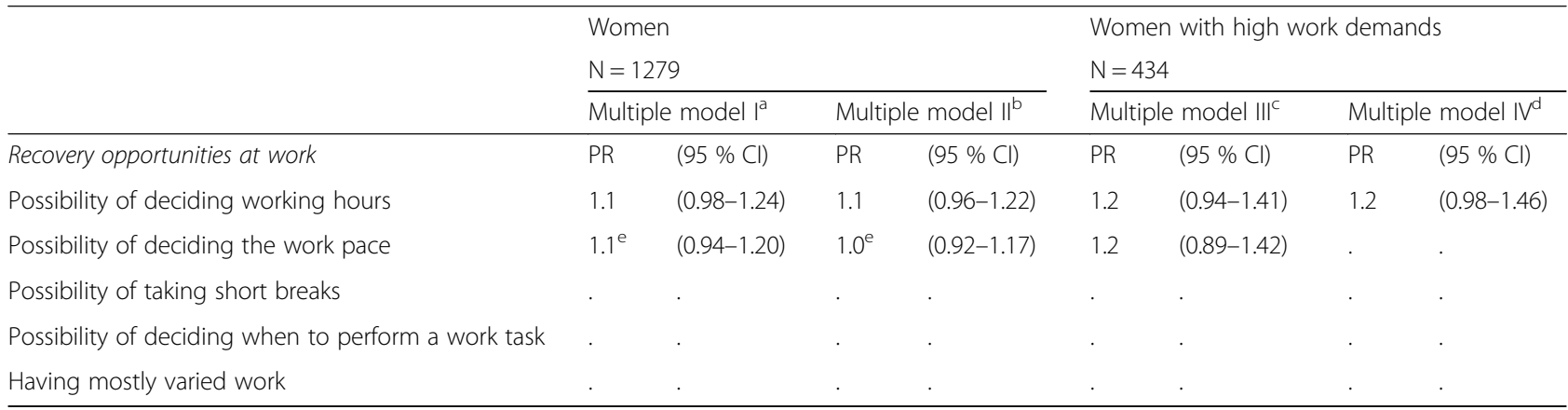

${ }^{\mathrm{a}}$ Multiple model with no confounders. ${ }^{\mathrm{b}}$ Multiple model with two confounders: high work demands and educational level. ${ }^{\mathrm{c}}$ Multiple model for the subsample with no confounders. ${ }^{\mathrm{d}}$ Multiple model for the subsample with one confounder: educational level. ${ }^{\mathrm{e}}$ Variable included only to adjust the multiple model ( $N$ number of workers included in the multiple analyses, $P R$ prevalence ratios, $95 \% \mathrm{Cl}=95 \%$ confidence interval, . = the variable was not included in the multiple model)

demands who reported possibility of deciding working hours (PR $=1.2$, models III and IV).

\section{Discussion}

To have varied work was found to be a recovery opportunity associated with excellent work ability for young men. In addition, for men with high work demands, the possibility of deciding when to perform a work task was also associated with excellent work ability. For young women with high work demands, the recovery opportunity to decide one's own working hours was associated with excellent work ability.

\section{Associations between recovery opportunities at work and excellent work ability}

The most distinct finding in the current study was that young men with varied work seemed most likely to experience excellent work ability. The recovery obtained from varied work among the men can probably include both the possibility to take breaks, which has been shown to maintain performance among adult workers [9], and the possibility of deciding the work pace, both of which are in line with a theoretical framework of recovery in relation to variety in the job setting [14]. A review of studies in work physiology has clearly shown that variation in physical workload has a significant influence on recovery in relation to musculoskeletal disorders [25]. Creating varied work content could therefore contribute to promoting excellent work ability in young men, especially since younger workers tend to have more monotonous work than older workers [2].

The association between varied work and excellent work ability was not, however, any stronger for young men with high work demands. This indicates that varied work is important for excellent work ability, independent of the level of work demands. Further, the different results for varied work in women and men might be explained by gender segregation of different work tasks in the labour market [26], with different contributions to variation of work postures and work movements. Even in the same occupation it is known that work tasks often differ between women and men [27], and men are therefore more likely able to create variation in their work.

Table 5 Prevalence ratios. Prevalence ratios based on multiple regression models for associations between recovery opportunities at work and excellent work ability for young men

\begin{tabular}{|c|c|c|c|c|c|c|c|c|}
\hline \multirow[b]{4}{*}{ Recovery opportunities at work } & \multirow{2}{*}{\multicolumn{4}{|c|}{$\begin{array}{l}\text { Men } \\
\mathrm{N}=1025\end{array}$}} & \multirow{2}{*}{\multicolumn{4}{|c|}{$\begin{array}{l}\text { Men with high work demands } \\
N=345\end{array}$}} \\
\hline & & & & & & & & \\
\hline & \multicolumn{2}{|c|}{ Multiple model I } & \multicolumn{2}{|c|}{ Multiple model II } & \multicolumn{2}{|c|}{ Multiple model III } & \multicolumn{2}{|c|}{ Multiple model IV ${ }^{d}$} \\
\hline & $P R$ & $(95 \% \mathrm{Cl})$ & PR & $(95 \% \mathrm{Cl})$ & $P R$ & $(95 \% \mathrm{Cl})$ & $P R$ & $(95 \% \mathrm{Cl})$ \\
\hline Possibility of deciding working hours & . & . & . & . & & . & . & . \\
\hline Possibility of deciding the work pace & 1.1 & $(0.96-1.29)$ & 1.1 & $(0.96-1.29)$ & 1.2 & $(0.90-1.49)$ & $1.1^{\mathrm{e}}$ & $(0.85-1.42)$ \\
\hline Possibility of taking short breaks & 1.1 & $(0.95-1.26)$ & $1.1^{e}$ & $(0.93-1.24)$ & & . & . & . \\
\hline Possibility of deciding when to perform a work task & 1.1 & $(0.97-1.30)$ & 1.1 & $(0.96-1.29)$ & 1.2 & $(0.93-1.52)$ & 1.3 & $(0.96-1.60)$ \\
\hline Having mostly varied work & 1.3 & $(1.10-1.46)$ & 1.3 & $(1.10-1.45)$ & 1.3 & $(0.99-1.61)$ & 1.3 & $(1.01-1.67)$ \\
\hline
\end{tabular}

${ }^{a}$ Multiple model with no confounders. ${ }^{b}$ Multiple model with two confounders: high work demands and educational level. ${ }^{c}$ Multiple model for the subsample with

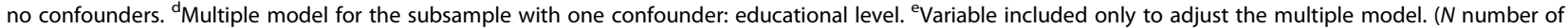
workers included in the multiple analyses, $P R$ prevalence ratios, $95 \% \mathrm{Cl}=95 \%$ confidence interval, . = the variable was not included in the multiple model) 
For men with high work demands, the possibility of deciding when to perform a work tasks was also found to be associated with excellent work ability. This recovery opportunity is included in the concept "global worktime control", associated with job satisfaction, but not with performance or productivity [8]. Hence, the result of work ability in the current study has not, to our knowledge, been presented earlier.

Enabling women with high work demands to decide their own working hours could be a promising way to promote excellent work ability. This result is in line with earlier studies among adult workers. Having flextime has been shown to have an impact on job satisfaction [8] and a positive effect on productivity [10], although previously reported results were not specific for young women. Adult women with poor health and the opportunity to adjust their worktime were prospectively associated with increased work ability and return to work [28]; however, a large part of that study's sample had poor work ability at baseline, which casts doubt on the appropriateness of a direct comparison with results of the current study. As no other recovery opportunities at work were found in the present study to be associated with excellent work ability among young women, other external factors such as duration and/or quality of sleep and/or relaxation between work-days may, in our opinion, be more important to their maintaining excellent work ability. Consequently, the situation could be more complex for young women, and possible important recovery opportunities were not taken into account in this study.

\section{Methodological considerations}

Obvious strengths of this study include its large population sample of a group not earlier investigated, but it also has limitations. The high proportion of young workers reporting excellent work ability and reporting high work ability in general might have muted the contrasts between exposed and unexposed groups and at least in part account for the small effects that were found. Furthermore, the limited scope of taking only internal recovery into account could make interpretations of the results uncertain, but probably contributes to a clearer focus.

The possible cohort effects in the current study may be an additional weakness as the sample was selected from different years. This sampling method of using surveys from three subsequent years was selected to obtain large groups for a study sample stratified for gender and further divided into subsamples with high work demands, while retaining enough power in the statistical analyses. Although the general work environment did actually change over the six years of the study [2], there is no reason to assume that possible associations between recovery opportunities at work and excellent work ability should also have changed substantially.
Excellent work ability can be measured in different ways. In the present study, as in earlier studies [3, 16], the cutoff for excellent work ability was 10 on the WAS. However, scores of 9-10 on the WAS have also been used for young workers [13, 29], in circumstances where choosing a score of 10 would have resulted in too few cases. Because self-rated work ability was high in the study sample, 10 on the WAS was considered appropriate for excellent work ability.

The questions in the telephone interview and the questionnaire were validated by Statistics Sweden, as occupational demands can be difficult to assess by self-reported exposure [30]. The validation procedure for these questions has been carefully described [15], and the questions used in the self-reported questionnaire were found to give reliable descriptions of actual work environments and conditions. Following that validation study, further work to increase the validity and reliability of the questions was also undertaken by Statistics Sweden; however, this work has not been carried out to a large extent since 2009, so the questions set for the three cohorts in the present study were nearly identical in formulation.

The choice of age group in the study sample warrants discussion. The upper age limit of 29 follows the limit for young workers used by Statistics Sweden, although their group starts at 16 years old. The lower limit of 18 years was chosen because most young adults aged 16-18 years continue in high school, and we wanted to examine young people at work.

The main limitation of the present study is the crosssectional study design, which hinders interpretation of possible causal associations. Despite this limitation, however, the study has some obvious strengths. The design of a population-based register study is a broad attempt to capture the topic among a large group of young employees, and the well-described method selected for building the multiple models can be seen as an advantage. Furthermore, the research topic is, to our knowledge, poorly investigated in young workers, despite its possible importance to a sustainable working life for this young group.

\section{Applications}

The results of this study could be used when planning organizational actions to promote excellent work ability among young workers. Varied work might contribute to excellent work ability in men and plausibly a healthier workplace for all employees [31, 32]. Also, facilitating worktime control could be one way to promote excellent work ability, especially for women with high work demands, though the awareness of other opportunities for recovery at work and in leisure may be more important. Further studies, longitudinal or qualitative, are greatly needed to explore how recovery opportunities through 
the workplace can contribute to excellent work ability among young working women and men.

\section{Conclusions}

For young men, having varied work can contribute to excellent work ability. In addition, for men with high work demands, the possibility of deciding when to perform a work task may be favourable for excellent work ability. For young women with high work demands, the possibility of deciding one's working hours can contribute to excellent work ability. Employers could use these opportunities for recovery in promoting work ability among young workers.

\section{Acknowledgements}

We wish to thank everyone involved in this project.

\section{Funding}

FORTE; Swedish Research Council for Health, Working life and Welfare contributed with funding to this study. This organization has no role in the design of the study and collection, analysis, and interpretation of data and writing the manuscript.

\section{Availability of data and materials}

Data and materials are stored at Occupational and Environmental Medicine, Gothenburg University. The data will not be shared due to other ongoing research projects using the material. In addition, all use of original data is legally limited by Statistics Sweden.

\section{Authors' contributions}

$\mathrm{MB}, \mathrm{JS}, \mathrm{MH}$, and $\mathrm{AE}$. designed the study. MB. carried out the data analysis and the interpretation of the data with help from AE. MB. wrote the manuscript, and JS, MH, and AE. discussed the manuscript with MB. and contributed to its final form. All researchers have read and approved the manuscript.

\section{Competing interests}

The authors declare that they have no competing interests.

\section{Consent for publication}

Not applicable.

\section{Ethics approval and consent to participate}

All procedures performed in studies involving human participants were in accordance with the ethical standards of the institutional and/or National Research Committee and with the 1964 Helsinki declaration and its later amendments or comparable ethical standards. Informed consent was obtained from all individual participants included in the cohort by Statistics Sweden when agreed to participate in the telephone interview and the questionnaire. This study was approved by the Regional Ethical Review Board at the University of Gothenburg, Sweden (Reg.no. 221-15).

\section{Author details}

'Department of Occupational \& Environmental Medicine, Sahlgrenska University Hospital, Postal: Box 414SE 40530 Gothenburg, Sweden. ${ }^{2}$ Academic Medical Center, Department: Coronel Institute of Occupational Health, PO Box 227001100 DE Amsterdam, The Netherlands. ${ }^{3}$ Health Metrics, Sahlgrenska Academy, University of Gothenburg, Gothenburg, Sweden.

Received: 18 May 2016 Accepted: 9 September 2016 Published online: 15 September 2016

\section{References}

1. IImarinen J. Work ability-a comprehensive concept for occupational health research and prevention. Scand J Work Environ Health. 2009;35(1):1-5.
2. Swedish Work Environment Authority: Arbetsmiljön 2013. The working environment 2013]. In Swedish. Stockholm: Swedish Work Environment Authority; 2014

3. Gould R, Ilmarinen J, Järvisalo J, Koskinen S: Dimension of work ability: Results of the Health 2000 Survey. Vaasa: Finnish Centre of Pensions, The Social Insurance Institution, National Public Health Institute, Finnish Institute of Occupational Health; 2008.

4. van Veldhoven MJ, Sluiter JK. Work-related recovery opportunities: testing scale properties and validity in relation to health. Int Arch Occup Environ Health. 2009;82(9):1065-75.

5. Jansen NW, Kant I, van den Brandt PA. Need for recovery in the working population: description and associations with fatigue and psychological distress. Int J Behav Med. 2002:9(4):322-40.

6. Sonnentag S, Zijlstra FR. Job characteristics and off-job activities as predictors of need for recovery, well-being, and fatigue. J Appl Psychol. 2006;91(2):330.

7. Joyce K, Pabayo R, Critchley JA, Bambra C: Flexible working conditions and their effects on employee health and wellbeing. Cochrane Database Syst Rev 2010(2). doi: 10.1002/14651858.CD008009.pub2.

8. Nijp HH, Beckers DG, Geurts SA, Tucker P, Kompier MA. Systematic review on the association between employee worktime control and work-nonwork balance, health and well-being, and job-related outcomes. Scand J Work Environ Health. 2012;38(4):299-313.

9. Tucker $P$. The impact of rest breaks upon accident risk, fatigue and performance: a review. Work Stress. 2003;17(2):123-37.

10. Baltes BB, Briggs TE, Huff JW, Wright JA, Neuman GA. Flexible and compressed workweek schedules: A meta-analysis of their effects on workrelated criteria. J Appl Psychol. 1999;84(4):496.

11. Boström M, Holmgren K, Sluiter JK, Hagberg M, Grimby-Ekman A. Experiences of work ability in young workers: an exploratory interview study. Int Arch Occup Environ Health. 2016;89(4):629-40.

12. Löve J, Hagberg M, Dellve L: Balancing extensive ambition and a context overflowing with opportunities and demands: A grounded theory on stress and recovery among highly educated working young women entering male-dominated occupational areas. Int J Qual Stud Health Well-being 2011, 6(3), doi:10.3402/ahw.v6i3.5904.

13. Seitsamo J, Tuomi K, Ilmarinen J. Work ability of young workers. In: Gould R, IImarinen J, Järvisalo J, Koskinen S, editors. Dimension of work ability: Results of the Health 2000 Survey. Helsinki: Finnish Centre of Pensions, The Social Insurance Institution, National Public Health Institute, Finnish Institute of Occupational Health; 2008.

14. Geurts SA, Sonnentag S. Recovery as an explanatory mechanism in the relation between acute stress reactions and chronic health impairment. Scand J Work Environ Health. 2006;32(6):482-92.

15. Wikman A: Att utveckla sociala indikatorer: en surveyansats belyst med exemplet arbetsmiljö. To develope social indicators: a survey attempt illustrated with the example work environment]. Stockholm: Statistiska centralbyrån [Statistics Sweden]; 1991

16. El Fassi M, Bocquet V, Majery N, Lair ML, Couffignal S, Mairiaux P. Work ability assessment in a worker population: comparison and determinants of Work Ability Index and Work Ability score. BMC Public Health. 2013;13(1):305.

17. Roelen C, van Rhenen W, Groothoff JW, van der Klink J, Twisk J, Heymans M. Work ability as prognostic risk marker of disability pension: single-item work ability score versus multi-item work ability index. Scand J Work Environ Health. 2014;40(4):428-31.

18. Takahashi M, Iwasaki K, Sasaki T, Kubo T, Mori I, Otsuka Y. Sleep, fatigue, recovery, and depression after change in work time control: a one-year follow-up study. J Occup Environ Med. 2012;54(9):1078-85.

19. Bossema ER, Kool MB, Cornet D, Vermaas $P$, de Jong M, van Middendorp $H$, Geenen R. Characteristics of suitable work from the perspective of patients with fibromyalgia. Rheumatology. 2012;51(2):311-8.

20. Swedish Work Environment Authority: Belastningsergonomi. [Strain ergonomic]. In: Arbetsmiljöverkets författningssamling [The collection of statues] In Swedish. Stockholm: Swedish Work Environment Authority; 2012

21. van den Berg $T I$, Elders $L A$, de Zwart BC, Burdorf $A$. The effects of workrelated and individual factors on the Work Ability Index: a systematic review. Occup Environ Med. 2009;66(4):211-20.

22. Messing K, Silverstein BA. Gender and occupational health. Scand J Work Environ Health. 2009;35(2):81-3.

23. Agresti A. Categorical data analysis. New York: Wiley-Interscience Publication; 2002. 
24. Hosmer DW, Lemenshow S. Applied Logistic Regression. Secondth ed. New York: Wiley-Interscience Publication; 2000.

25. Swedish Work Environment Authority: Fysisk variation och belastningsbesvär i arbetet. [Physical variation and strain injuries at work]. In Swedish. Stockholm: Swedish Work Environment Authority; Report 2016:1; 2016.

26. Statistics Sweden: På tal om kvinnor och män. Lathund om jämställdhet 2014. [Women and men in Sweden - Facts and figures 2014]. In Swedish. Stockholm: Statistics Sweden; 2014

27. Abrahamsson L. Att återställa ordningen. [To restore the order]. Swedish: Boréa bokförlag; 2009.

28. Dellve L, Fallman SL, Ahlstrom L. Return to work from long-term sick leave a six-year prospective study of the importance of adjustment latitudes at work and home. Int Arch Occup Environ Health. 2016;89(1):171-9.

29. von Bonsdorff ME, Kokko K, Seitsamo J, von Bonsdorff MB, Nygard CH, Ilmarinen J, Rantanen T. Work strain in midlife and 28-year work ability trajectories. Scand J Work Environ Health. 2011;37(6):455-63.

30. Barrero LH, Katz JN, Dennerlein JT. Validity of self-reported mechanical demands for occupational epidemiologic research of musculoskeletal disorders. Scand J Work Environ Health. 2009;35(4):245-60.

31. Luger $T$, Bosch $T$, Veeger $D$, de Looze $M$. The influence of task variation on manifestation of fatigue is ambiguous-a literature review. Ergonomics. 2014:57(2):162-74.

32. Balogh I, Ohlsson K, Nordander C, Björk J, Hansson G- $\AA$. The importance of work organization on workload and musculoskeletal health-Grocery store work as a model. Appl Ergon. 2016;53:143-51.

\section{Submit your next manuscript to BioMed Central and we will help you at every step:}

- We accept pre-submission inquiries

- Our selector tool helps you to find the most relevant journal

- We provide round the clock customer support

- Convenient online submission

- Thorough peer review

- Inclusion in PubMed and all major indexing services

- Maximum visibility for your research

Submit your manuscript at www.biomedcentral.com/submit 